http://jmscr.igmpublication.org/home/ ISSN (e)-2347-176x ISSN (p) 2455-0450 crossref DOI: https://dx.doi.org/10.18535/jmscr/v8i2.77

\author{
(D) Journal Of Medical Science And Clinical Research

\title{
Surgical Management of Skin Cancer
}

\author{
Authors \\ Dr Hyma Sree Gorusu ${ }^{1}$, Dr Sushama Surapaneni², Dr Susmitha Pragada ${ }^{3}$ \\ General Surgery Department, NRI General Hospital, Mangalagiri, Guntur District, \\ Andhra Pradesh, 522503, India
}

\begin{abstract}
Skin cancer is most common, accounting half of all malignant neoplasms. Basal cell carcinoma and Squamous cell carcinoma include the bulk of skin cancer, but melanoma is considered the most common cause of skin cancer related death. This is a prospective study, to analyse the clinical presentations, diagnosis, epidemiology and various surgical treatment modalities in management of skin malignancies.

Keywords: Skin cancer, Basal cell carcinoma, Squamous cell carcinoma.
\end{abstract}

\section{Introduction}

Skin malignancies constitute about half of all malignant neoplasms. One in every five individuals are affected with skin cancer in United States.

While cancers of the skin generally are more amendable to therapeutic measures than are cancers of other sites, accurate diagnosis has been difficult due to variations in histological types. Interpretation of clinical picture is also difficult, for identical manifestations resembling widely different causes. However, the great advantage in cutaneous surgery is that of dealing with an organ that can be seen and felt.

\section{Materials and Methodology}

Our study includes 30 cases presenting in OPD, complaining of skin lesions. Most of the cases are admitted with frank clinically diagnosable lesions, a few days prior to surgery. But a few cases are investigated with doubtful or confusing lesions before surgery.

Once patients are admitted to the hospital, a detailed history with special references to facts like age, occupation, type of lesions, site, any predisposing factors are enquired. A thorough history of familial incidence is enquired.

The local examination includes size, shape, extent of the lesion, number of lesions, floor, edge, surrounding area, induration, tenderness and bleeding is noted with special reference to fixity and relation to deeper structure. Regional lymph nodes are carefully evaluated by number, size, shape, tenderness, consistency, mobility and pressure effects or deformities. Examination for distant lesion like in-transit metastasis or satellite nodules is done. Systemic examination includes search for metastasis liver, lungs etc., Any systemic diseases producing metastasis in skin are excluded. 


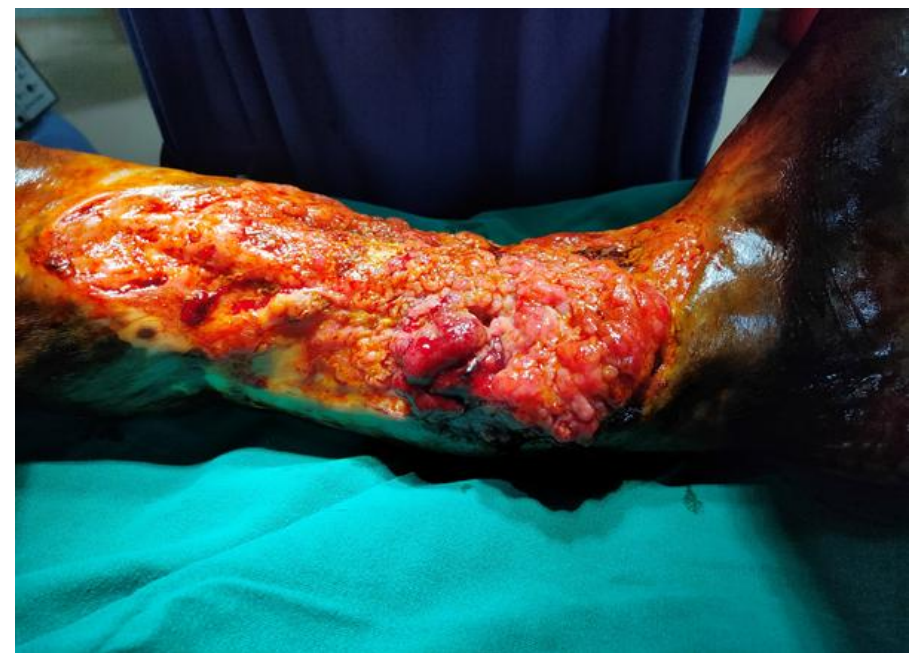

Figure 1 Ulcero-proliferative skin lesion over the leg

All the data is entered at the time of admission in a standard pretexted proforma. Management and follow up are further added in the proforma.

Once the provisional diagnosis is made as a primary skin malignancy, a discussion is carried with respective unit chief on the mode of management and most of the lesions were subjected to the biopsy. IHC markers are investigated postoperatively when provisional diagnosis is doubtful. General investigations like Complete blood picture, renal function tests, chest X ray, ECG are done to get a medical fitness for surgery.

Specific investigations like X-ray of the part and FNAC of Regional LN is done for the treatment and prognostic aspect of management. Small lesions are subjected to excisional biopsy and big lesions for edge biopsy. In ulcero-proliferative and ulcerative lesions with presentation of infection and inflammation no attempt is made to study the bacteriological flora. All are treated palliatively or curatively and if wound gets infected appropriate antibiotic based on culture report is started postoperatively. Pre-operative antibiotics are administered in all patients and continued postoperatively according to necessity.

The methods and mode of operation are discussed with patients and consent taken after explaining the pros and cons of each method. For mutilating surgeries special consent is taken, some patients are subjected to chemotherapy following excision depending on the need. Post-operatively rehabilitation counselling is done.

\section{Results}

Out of the 30 cases presented in the OPD with skin lesions, 17 are SCC, 9 are BCC and 4 are melanoma. 19 are male and 11 are female, with male: female ratio being 1.7:1. There is also a steep increase in malignant skin cancers after $6^{\text {th }}$ decade. About $60 \%$ of the lesions are ulcero-proliferative followed by ulcerative type.

\section{Epidemiology of cutaneous malignancies}

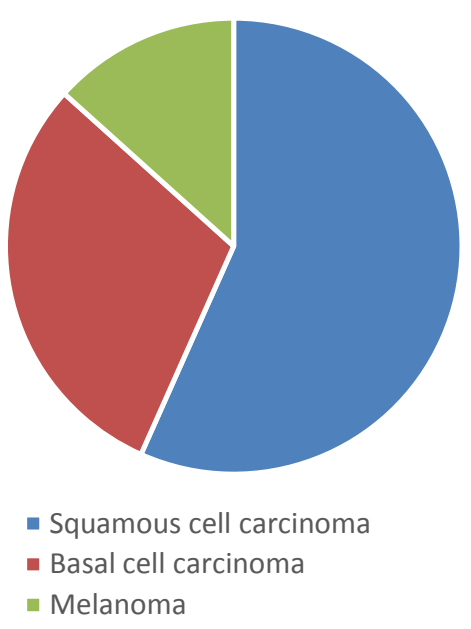

In this study, the sites of distribution of the lesions is predominantly over the lower extremities followed by face. The affected parts of the body are commonly the sun exposed parts of the body. 3 out of 17 SCC patients had ulcero-proliferative lesions developed over a burns scar. Basal cell carcinoma all cases occurred on the face in our study $(100 \%)$. The mode of presentation is either a solitary nodule or ulcer.The patients underwent various surgical treatments depending upon their condition. Most of the patients underwent wide local excision followed by radiotherapy to preventlocal recurrence. Regional lymph node dissection is done in 6 patients of which 3 of them showed positive metastasis. 4 of the patients developed secondary wound infection treated by antibiotics and mechanical debridement.

An attempt was made to follow up the cases following curative surgeries. But because of illiteracy, poverty and negligence on part of patients follow up of the patients was poor, 2 of the patients 
had regional lymph node involvement after one year. 3 of them showed local recurrence.

Table. No 1 Curative surgeries of cutaneous skin malignancies

\begin{tabular}{|l|c|c|}
\hline S.no & Surgical Procedure & No. of patients \\
\hline 1. & $\begin{array}{c}\text { Wide local excision with } \\
\text { primary closure }\end{array}$ & 6 \\
\hline 2. & $\begin{array}{c}\text { Wide local excision with } \\
\text { immediate skin grafting }\end{array}$ & 10 \\
\hline 3. & $\begin{array}{c}\text { Wide local excision with } \\
\text { healing by secondary } \\
\text { intention }\end{array}$ & 9 \\
\hline 4. & $\begin{array}{c}\text { Wide local excision by } \\
\text { myocutaneous flap }\end{array}$ & 4 \\
\hline 5. & Amputations & \\
\hline
\end{tabular}

\section{Discussion}

Cutaneous malignancies are of two typesMelanoma and Non-melanoma skin cancers (NMSC). NMSC is the most common human cancer, with an estimated annual incidence of $>3$ million in 2006 in the United States, higher than the incidence of lung cancer, breast cancer, prostate cancer, and colon cancer combined ${ }^{[1-3]}$. A 2013 meta-analysis estimated the number of new NMSC cases in United states to be between 186,000 and 419,000 in 2012 ${ }^{[4]}$. The NMSC constituting mostly the Basal cell carcinoma (BCC) and Squamous cell carcinoma (SCC).

There is a dramatic increase in the incidence of NMSC with increase in age i.e. for those over 75 , it is 5 to 10 times more than younger age groups ${ }^{[5,6]}$. Geographic variability is seen as there is a higher incidence of cutaneous SCC in regions closer to the equator $^{[7]}$.

Males are commonly affected compared to females. A high incidence of skin cancer is seen in agricultural workers who work for long hours in the fields with prolonged sunlight exposure ${ }^{[8]}$.

There is increased risk of skin cancer in organ transplant recipients attributed to their chronic exposure to immunosuppressive agents ${ }^{[9,10]}$.

Lesions and lower extremity predominate followed by lesions on head and neck. Among all these lesions in lower limbs squamous cell carcinoma occurs maximum. This may be due to repeated trauma and infection to that part. A line joining the lobule of ear to ala of nose is the common occurrence site for basal cell carcinoma (100\%). This again in relation to increased sun exposure. Treatment principles in a majority of cases included a biopsy to confirm diagnosis. The age, number of lesions, the size, tumor border, recurrent squamous cell carcinoma and anatomic site are important when planning wide local excision.

\section{Conclusions}

Primary malignant tumors of skin are one of the commonest cancers in India. Although it has not reached epidemic proportion as in western countries it is a highly relevant study for the surgeon because of the variety of clinical presentation and treatment possibilities available. The risk of skin malignancies can substantially be reduced by limiting the sun exposure and using sunscreen, hats, and sunprotective clothing.

\section{References}

1. Madan V, Lear JT, Szeimies RM. Nonmelanoma skin cancer. Lancet 2010; 375:673-685.

2. Stern RS. Prevalence of a history of skin cancer in 2007: results of an incidence-based model. Arch Dermatol 2010; 146:279-282.

3. Rogers HW, Weinstock MA, Harris AR, et al. Incidence estimate of nonmelanoma skin cancer in the United States, 2006. Arch Dermatol 2010; 146:283-287.

4. Karia PS, Han J, Schmults CD. Cutaneous squamous cell carcinoma: estimated incidence of disease, nodal metastasis and deaths from disease in the united states, 2012. J Am Acad Dermatol 2013; 68:957.

5. Karagas MR, Greenberg ER, Spencer SK, et al. Increase in incidence rates of basal cell and squamous cell cancer in New Hampshire, USA. New Hampshire Skin Cancer Study Group. Int J Cancer 1999; 81:555.

6. Gray DT, Suman VJ, Su WP, et al. Trends in the population-based incidence of squamous cellcarcinoma of the skin first diagnosed 
between 1984 and 1992. Arch Dermatol 1997; 133:735.

7. Green A, Battistutta D, Hart V, et al. Skin cancer in a subtropical Australian population: incidence and lack of association with occupation. The Nambour Study Group. Am J Epidemiol 1996; 144:1034.

8. Gallagher RP, Hill GB, Bajdik CD, et al. Sunlight exposure, pigmentation factors, and risk of nonmelanocytic skin cancer. II. Squamous cell carcinoma. Arch Dermatol 1995; 131:164.

9. Hartevelt MM, Bavinck JN, Kootte AM, et al. Incidence of skin cancer after renal transplantation in The Netherlands. Transplantation 1990; 49:506.

10. Jensen P, Hansen S, Moller B, et al. Skin cancer in kidney and heart transplant recipients and different long-term immunosuppressive therapy regimens. J am Acad Dermatol 1999; 40:177 